\title{
South African Adults at Risk of Overweight and Obesity: an Assessment of the Association of Food Choices and Body Mass Index in Khayelitsha and Mitchells Plain
}

\author{
Mulugeta F. Dinbabo \\ (Corresponding Author) \\ Institute for Social Development, University of the Western Cape, South Africa \\ Email: mdinbabo@uwc.ac.za \\ Michael Nguatem Belebema \\ Institute for Social Development, University of the Western Cape, South Africa \\ Clement Mensah \\ Institute for Social Development, University of the Western Cape, South Africa \\ DOI//http://dx.doi.org/10.4314/gjds.v16i3.3
}

\begin{abstract}
South Africa is experiencing a rapid increase in its urban townships population as well as increase in overweight and obesity, especially amongst adult women. This study investigates on the association of Body Mass Index and food choices in two urban townships - Khayelitsha and Mitchells Plain in Cape Town. About 4328 individuals from 1051 households were interviewed and anthropometric data drawn from the population. Principal component analysis was conducted on 36 food choices using a 24-hour recall. Average Dietary Diversity Score (DDS) was 3.88 which was less than the South African average. Seven food patterns were identified and contribute $80 \%$ of the variations. The results show that about $60 \%$ of adults' sampled were overweight and obese at BMI $25 \mathrm{~kg} / \mathrm{m}^{2}$. DDS was significantly low for most individuals ( $\mathrm{p}=0.032$ ) despite $90 \%$ of food prepared at home. The study concludes that inconsistent and distorted dietary patterns and socioeconomic status affected access to food choices that is evidence of balanced diet, and thereby creating an avenue for the risk of overweight and obesity. Consumer awareness programmes that focus on reducing the risk of obesity needs to be put in place in poor communities to address the problem and risk of poor food choice and obesity.
\end{abstract}


Keywords: South Africa, Food, Obesity, Overweight and Poverty

\section{INTRODUCTION}

Overweight and obesity has become a major public health concern worldwide. Women are most susceptible to becoming obese. In 2014, more than 1.9 billion adults were classified as overweight, about $39 \%$ of adults worldwide. Of these, 600 million were obese, translating into a total of $13 \%$ of the world's adult population (WHO, 2016). The report also stated that between 1980 and 2014, the worldwide prevalence of obesity more than doubled. The increasing incidence of overweight and obesity and its accompanying health risks place a major burden on individuals, communities and health care systems throughout the world (Goedecke et al. 2005; Jones-Smith et al., 2012; Kanter \& Cabellero, 2012; Loring \& Robinson, 2014; WHO, 2016).

In Africa, the prevalence of overweight and obesity differs across region, states and gender. Ng et al. (2014) show evidence of these disparities in North African Countries; Libyan women had the highest obesity incidence at 57.2\%, whilst 30.2\%of Libyan men were classified as obese. Asfaw (2006) found that South African and Senegalese obese patients were far more likely to face the risks of arthritis, asthma, diabetes, and heart diseases than their lean counterparts. Adeboye, Bermano and Catherine (2012) examined the pattern of obesity in Africa. Their investigation confirmed other findings which indicated a higher prevalence of obesity in urban areas. It pointed to changing food consumption patterns, increased availability of processed foods and less physical activity as contributing factors.

\section{Background of the Study}

Over the last nine years, the South African Government has spent more than R23 billion treating illnesses directly linked to obesity (Mapumulo, 2015). It is predicted that the incidence of non-communicable lifestyle diseases will exceed that of infectious diseases in the near future and the cost to healthcare systems will amount to approximately R8 billion per year (Mapumulo, 2015). Several studies have found strong evidence of obesity eating the fabrics of the South African society. A study conducted between 2008 and 2013 revealed that $42 \%$ of women in South Africa were obese, which is the highest level of obesity in sub-Saharan Africa (Ng et al., 2014).

The National Income Dynamics Study (NIDS) indicates that more than one-third of women over the age of 18 are obese whilst only $11 \%$ of men were found to be obese. The 2012 South African National Health and Nutrition Survey (SANHANES-1) report 
confirms the NIDS 2008 findings with $39.2 \%$ of women classified as obese compared to only $10 \%$ of men who were considered obese (DOH, 2015).

Given that obesity and associated risk continue to raise concerns amongst researchers and policy makers in South Africa, not many studies have investigated food choices of people living in urban peripheries in South Africa, and linking their food choices to overweight and obesity. This research is part of a national strategy to understand some of the drivers of overweight and obesity especially amongst the poor. The paper examines the links between food choices and BMI amongst adults in Khayelitsha and Mitchells Plain in Cape Town as well its correlation to the sociodemographic characteristics of the population.

The latest available national data in South Africa on nutrition and health is found in the South Africa National Health and Nutrition Examination Survey (SANHANES-1) conducted in 2013. The findings of SANHANES-1 do not provide anthropometric data for current BMI amongst adults. However, studies carried out by the Human Science Research Council (HSRC) states that more than $63 \%$ of South African women and about $69 \%$ of men are happy with their body weight (HSRC \& MRC, 2013). Reflecting on the overall findings in the literature, leads to conclusion that obesity is on the rise in South Africa and amongst one of the highest in sub-Saharan Africa. One of the challenges in addressing obesity problem in South Africa is that the majority of its citizens do not seem to perceive obesity as a health risk or problem as evidenced in Devanatha et al. (2013: 4) and Hoffmann (2013).

Numerous data sources reveal that women are more likely to be obese than men (Prentice, 2005). This is attributed to physical activity variances, sociocultural factors and biological differences (Kanter \& Cabellero, 2012). From the period 1975 to 2014, world obesity has tripled in terms of the number of people who are obese. An analysis of over 19 million people in two hundred countries show increased gender disparities in BMI amongst adults (NCD Risk Factor Collaboration, 2016). NCD Risk Factor Collaboration (2016) further states that the age-standardized prevalence of obesity for men increased from 3\% in 1975 to $10 \%$ in 2014 whilst obesity in women increased from 6\% in 1975 to $15 \%$ in 2014. Loring and Robinson (2014) note that one of the reasons that women tend to be more obese is that they are less likely to participate in physical activity due to traditional gender norms which discourage teenage girls' and women's participation in organised physical activity. This perception is however different in the study area where some researchers have found that women in Khayelitsha see physical activity/ exercise as a strategy for weight loss (BMC Public Health, 2015; Draper, et al. 2016). Other barriers to participating in physical activities for women and children in urban areas include safe places to exercise, particularly in low income, disadvantaged areas. While 
many studies confirm that BMI rises with increased age amongst both male and female adults, there is a significant correlation between increased body fat and the postmenstrual period for women (Kruger et al. 2009).

\section{METHODOLOGY}

Data for this study was drawn from the 2016 Khayelitsha and Mitchells Plain Survey, funded by the Programme to Support Pro-poor Policy Development (PSPPD) and the Center of Excellence for Food Security at the University of the Western Cape. In the study, 1051 households were successfully interviewed representing $87 \%$ response rate. About 532 households from Khayelitsha and 519 from Mitchells Plain participated in the study, constituting a sample of 4327 individuals. Adults constituted $74 \%$ of the population. For purpose of this paper, only adults that were effectively measured for anthropometrics were included in the in this analysis. About 1500 adults were effectively measured for BMI analysis and constituted $45 \%$ of adult population 3174. The PSPPD project focused on assessing the prevalence of overweight and obesity in the study area and its association to people's food choices. The project report provides general descriptive analysis of the study. In this regard, this paper tests the association of food choices and BMI.

\section{Sampling Technique}

The study employed a two-stage cluster sampling technique. This involved selecting clusters of households using probability proportion to size (PPS) at the first stage and the actual selection of households in the second stage. The choice of cluster sampling technique over simple and systematic random sampling was informed by the fact that the two case study areas were too large geographically and due to the unavailability of lists of households in Khayelitsha and Mitchells Plain. Owing to this, previous surveys such as the Khayelitsha/Mitchells Plain 2000 Survey utilized a similar sampling method (Crankshaw et al., 2001).

In Stage 1, 25 EAs $^{3}$ were selected randomly using probability proportion to size. This was to ensure approximately equal probability of selection. In Stage 2-Selection of households, 24 households were systematically selected from each EA or cluster selected in stage 1 above, putting sample sizes for Khayelitsha and Mitchells Plain at 1051 households. In selecting households, geographic coordinates obtained from Stats SA were used to demarcate EAs. To ascertain the $\mathrm{k}^{\text {th }}$ house/household for an EA with 150 households, researchers divided the total number of households (150) by the expected number of households, which is 24 for each selected EA. This gives a $\mathrm{K}$

3 Enumeration Areas 
value of 6 . Thus, for this particular EA, every $6^{\text {th }}$ household identified was selected for an interview. This is relatively the same for other previous surveys conducted in the same case study areas (see for example Crankshaw et al., 2001).

\section{Data Analysis Structure}

Data obtained from the survey was statistically analyzed, with the aim of describing phenomena as well as identifying and examining relationships. STATA Version 14 was used to carry out all analytical procedures. As Kreuter and Valliant (2007) suggest, there are more analytical procedures for survey data in STATA version 14.

\section{Assessment of Obesity and Food Choices}

The WHO BMI standards were applied in this study. Researchers on BMI have used different methodologies such as weight for age and height for age to estimate body sizes. However, the most commonly acceptable standards for measuring BMI, which has been adopted in this research, is the BMI=Weight/Height ${ }^{2}$ measurement for an adult. These measures were classified as following using WHO guidelines for BMI cut offs: Underweight (BMI $\leq 18.5$ ), Normal Weight (BMI $\geq 18.5$ and $\leq 24.9$ ), Overweight BMI ( $\geq 25.0$ and $\leq 29.9)$, Obese Class 1 (BMI $\geq 30.0$ and $\leq 34.9)$, Obese Class 2 (BMI $\geq 35.0$ and $\leq 39.9)$, Obese Class 3 (BMI $\geq 40$ (WHO, 2006) (Wang and Chen, 2012).

\section{Developing the Food Groups to Identify Dietary Patterns}

Dietary Diversity Score (DDS) was used to determine food consumption and to assess whether person with high DDS are more likely to become obese. We develop 12 food groups for based on the 36 food choices reported by participants. Instead of a standardized Food Frequency Questionnaire provides by the FAO which stated 8 food groups, participants were rather given the opportunity to state what they ate during the 24-hour recall. The rational was that using the FAO food could have limited the identification of specific food types eaten by respondents since local food contents and composition vary by culture and race. Using an open ended question, respondents stated the type of food consumed which was considered to be their food choices. The objective was to minimise the chances of not being able to record food types that a pre-prepared list of food types may leave out. We measure the association between the size of the households, the demographics characteristics of the households, association of DDS and BMI. We used Principal Component Analysis (PCA) to develop food patterns and use ordinary least square regression to identify association between food group, food patterns and BMI. 


\section{RESULTS AND DISCUSSIONS}

\section{Socio-demographic Characteristics}

In this section we present the socio-demographic characteristics of the population. Gender distribution shows that $58 \%$ were females while males make up $42 \%$ of the population. While there were more male respondents in Mitchells Plain than in Khayelitsha, i.e. $46 \%$ and $40 \%$ respectively, there were more female respondents in Khayelitsha than in Mitchells Plain, 60\% and 54\% respectively. In general, adult aged $18+$ constitute $74 \%$ of the sample $(n=3175)$. Across South Africa, the proportion of households headed by women has risen because of the increased economic independence of women (due to the steady feminisation of employment and the expanded access to social grants) as well as changing marital and familial norms. In general, $67 \%$ of the population was between the ages 24 to 64 years and mean age was 37 for men and 38 for women.

Household size in South Africa is a key poverty indicator and is relevant for policy development (Maziya et al., 2017). Household sizes for both areas were similar. In Table 1, households with 4 persons or less constitute $41 \%$ while $34 \%$ live in households with 5 to 6 persons and 24\% live in households with 7 persons and more. Given that average household size was 5 persons, cumulatively $75 \%$ of the sampled population live in a household of 1 to 6 persons. Respondents were asked to report on the overall household income from all persons working or earning an income in the household. The income variable was categorised in range. About 808 households (77\%) reported on their household income. Table 1 show that $35 \%$ of households earned a monthly income of R1 to R2400. About 31\% of households earned income above R2401 to 4800 and 30\% earned above 4800 . About $5 \%$ of households earned No income. In 2016, the City Cape report show that $16 \%$ of population Khayelitsha and Mitchells Plain earn no income and 4.4\% earned income from R1 to R6 327. This is an indication of high levels of poverty in the area (City of Cape Town, 2016). 
Table 1: Household sizes and monthly income

\begin{tabular}{|c|c|c|c|c|c|c|}
\hline \multicolumn{7}{|c|}{ Monthly Household Income } \\
\hline & \multicolumn{2}{|c|}{ Khayelitsha } & \multicolumn{2}{|c|}{ Mitchells Plain } & \multicolumn{2}{|l|}{ Pooled } \\
\hline & $N=432$ & $\%$ & $N=376$ & \% & $\mathbf{N}=808$ & $\%$ \\
\hline No income & 34 & $8 \%$ & 5 & $1 \%$ & 39 & $5 \%$ \\
\hline R1-1200 & 79 & $18 \%$ & 23 & $6 \%$ & 102 & $13 \%$ \\
\hline $\mathrm{R} 1201-2400$ & 108 & $25 \%$ & 66 & $18 \%$ & 174 & $22 \%$ \\
\hline R2401-3600 & 69 & $16 \%$ & 76 & $20 \%$ & 145 & $18 \%$ \\
\hline R3601-4800 & 53 & $12 \%$ & 56 & $15 \%$ & 109 & $13 \%$ \\
\hline More than R 4800 & 89 & $21 \%$ & 150 & $40 \%$ & 239 & $30 \%$ \\
\hline \multicolumn{7}{|c|}{ Number persons living in households } \\
\hline & $\mathbf{N}=2159$ & $\%$ & $\mathbf{N}=\mathbf{2 1 6 9}$ & \% & $\mathrm{N}=4328$ & $\%$ \\
\hline$<=4$ persons & 898 & $42 \%$ & 891 & $41 \%$ & 1789 & $41 \%$ \\
\hline $5-6$ persons & 718 & $33 \%$ & 764 & $35 \%$ & 1482 & 34.24 \\
\hline 7+ Persons & 543 & $25 \%$ & 514 & $24 \%$ & 1057 & 24.42 \\
\hline
\end{tabular}

\section{Prevalence of Overweight and Obesity in Adults}

The result of the prevalence of BMI in the study areas showed that average BMI was $27 \mathrm{~kg} / \mathrm{m}^{2}$, and indicates a population that is highly overweight. In Table 2 we show that about $60 \%$ of adults sampled were overweight and obese. When disaggregated, $28 \%$ were overweight, $16 \%$ were in their first stage of obesity, $11 \%$ were in stage two obesity and $9 \%$ were in stage three obesity. The results portray a strong indication of the risk of the increase in overweight and obesity in urban townships in Cape Town.

Table 2: Prevalence of overweight

\begin{tabular}{|l|l|l|l|}
\hline Body Mass Index in \% of All Adults \\
\hline Weight Measure & Khayelitsha & Mitchells Plain & Total \\
\hline & $\mathrm{N}=748$ & $\mathrm{~N}=754$ & $\mathrm{~N}=1502$ \\
\hline Underweight & 11.23 & 10.74 & 10.99 \\
\hline Normal weight & 28.07 & 29.71 & 28.89 \\
\hline Overweight & 22.59 & 23.08 & 22.84 \\
\hline Obese class I & 16.84 & 16.31 & 16.58 \\
\hline Obese class II & 11.36 & 10.61 & 10.99 \\
\hline Obese Class III & 9.89 & 9.55 & 9.72 \\
\hline
\end{tabular}

Furthermore, comparing the two areas we found that about $38 \%$ in Khayelitsha compared to $36 \%$ in Mitchells Plain were obese. The percentage of normal weight 
for both areas averaged at $28.89 \%$. Overall, $22.84 \%$ were overweight and $37.29 \%$ were obese.

\section{Gender and BMI in Khayelitsha and Mitchells Plain}

Table 3 shows a gender perspective of BMI in the study area. The result show that $44 \%$ of males in Khayelitsha were obese compared to $36 \%$ of males in Mitchells Plain. About $26 \%$ of female respondents in Khayelitsha were of normal weight compared to $23 \%$ of females in Mitchells Plain. Generally females in bother areas were more overweight and obese than their male counterparts. Further, we found that females in Khayelitsha had a higher percentage of obesity compared to females in Mitchells Plain and the reverse was true for overweight where females in Mitchells Plain were more likely to be overweight compared to females in Khayelitsha. There was a significantly difference in BMI by gender. Using a ttest statistics, the mean BMI for female was 27.77 and mean BMI for males was 25.92 at p-value=0.0018. Overall, the study found that mean BMI was significantly higher for Khayelitsha than in Mitchells Plain $t=3.0420$ and $p$-value $=0.0012$. This evidence corroborates previous finding on the rise of obesity worldwide and in South Africa in particular Puoane et al. (2002); Amstrong et al. (2011); Ng et al. (2014); Mickelsfield et al. (2013); Kruger et al. (2005). $\mathrm{Ng}$ (2014) states that about $42 \%$ of adults and children suffering from overweight and obesity in sub-Saharan Africa are in South Africa. Thus, from a gender perspective, these results are evidence of weight gain in the study area which needs constructive intervention strategies. In the next section we associate BMI and food types.

Table 3: BMI by gender and region

\begin{tabular}{|l|l|l|l|l|}
\hline \multicolumn{2}{|l|}{ Overweight, obesity and gender of adults } \\
\hline BMI & \multicolumn{2}{l|}{ Khayelitsha } & \multicolumn{2}{l|}{ Mitchells Pain } \\
\hline & Male & Female & Male & Female \\
\hline Underweight & $14.56 \%$ & $14.75 \%$ & $15.95 \%$ & $16.67 \%$ \\
\hline Normal Weight & $23.79 \%$ & $26.23 \%$ & $22.41 \%$ & $23.23 \%$ \\
\hline Overweight & $16.99 \%$ & $22.95 \%$ & $23.71 \%$ & $26.77 \%$ \\
\hline Obese & $44.66 \%$ & $36.07 \%$ & $37.93 \%$ & $33.33 \%$ \\
\hline
\end{tabular}

\section{Association of BMI and Food Choices}

The main objective of this paper was to first identify the food choices of people living in urban peripheries in Cape Town. Given the high prevalence of household poverty in the study area, it was necessary to identify the type of food eat and how it could be linked to their weight gain. As already stated in the methodology, 36 food types were identified as the main food choices of the population. The 
food choices were then grouped in 12 food groups as in seen in Table 4. The Table attempts to link food choices and BMI. The results show that cereal produces such as mealies, food made from maize, white bread, traditional fried food made from flour also known locally as "Amagwenya", were the most dominant food eaten by the population. Overweight and obese persons eat high in cereal products, meat products and beverages which were most reported as alcohol or beer type drinks. The result indicates that poor communities in Cape Town could be living on a cereal based diet. About $28 \%$ of all food types consumed was cereal based which include, porridge, maize and cereal products

Table 4: Association of BMI and Food Groups

\begin{tabular}{|l|l|l|l|l|l|}
\hline \multicolumn{7}{|c|}{ BMI and food choices } & \multicolumn{2}{l|}{ Under } \\
\hline & $\begin{array}{l}\text { Normal } \\
\text { weight }\end{array}$ & $\begin{array}{l}\text { Overweight } \\
\text { weight }\end{array}$ & Obese & Total \\
\hline Food Groups & 27.18 & 28.57 & 29.25 & 27.44 & 28.06 \\
\hline White roots (potatoes) & 6.67 & 3.97 & 6.60 & 7.62 & 6.28 \\
\hline Vegetable (spinach, cabbage) & 6.67 & 10.32 & 9.43 & 8.23 & 8.71 \\
\hline Fruits (mango, orange) & 3.59 & 2.38 & 1.42 & 3.05 & 2.63 \\
\hline Fish (including canned fish) & 3.08 & 1.98 & 0.94 & 1.22 & 1.72 \\
\hline Meat (beef, pork, chicken) & 19.49 & 14.68 & 18.40 & 13.41 & 16.01 \\
\hline Legumes (peas, beans, nuts) & 2.05 & 2.38 & 1.89 & 2.44 & 2.23 \\
\hline Milk (yoghurt, cheese) & 2.05 & 5.56 & 6.60 & 6.10 & 5.27 \\
\hline Fat and oil & 3.08 & 2.38 & 4.25 & 2.13 & 2.84 \\
\hline Sweets (sugar) & 4.10 & 7.14 & 5.19 & 5.79 & 5.67 \\
\hline Condiments (spices, pepper) & 3.59 & 6.35 & 3.30 & 7.93 & 5.67 \\
\hline Beverages(tea, coffee) & 18.46 & 14.29 & 12.74 & 14.63 & 14.89 \\
\hline
\end{tabular}

Source: Authors analysis from empirical data

In order to assess the relationship between choices and body mass in the survey, respondents were asked if the food they ate was their usual food. The result showed that overall, $69.90 \%$ of the population indicated that the food they ate was their usual food compared to $30.10 \%$ who reported that what they ate was not their usual food. However, despite the percentage difference in their response, there was no statistically significant difference in their usual food as our $\mathrm{X}^{2}$ statistics was not significant at 95\% confidence interval (Pearson $\mathrm{X}^{2}=10.0935 \mathrm{P}$-value $=0.522$ ). The table provides a descriptive perspective of the association of body size and food types as reported during the 24-hour recall. Beverage was highly associated amongst underweight person in the samples. This evidence is consistent with low dietary divert that characterized the population of Khayelitsha and Mitchells Plain 
as shown below under Dietary Diversity section. While it can be deduced that there is a clear association between energy dense food and obesity, it cannot be concluded that it leads to causation since the cause of obesity is multifaceted. Food rich in micro-nutrients such as vegetables and fruits as wells as pulses were least consumed during the 24-hour recall. This evidence supports previous findings showing that South African poor are suffering from low dietary diversity as well as high level of cereal based diets (Labadarios et al., 2011 \& Du Plooy, et al. 2018).

\section{Dietary Diversity Score}

Dietary Diversity Score (DDS) was carried out based on the premise that no single food type can provide all the needed nutrients. DDS was conducted by counting the number of food groups consumed by an individual during the 24-hour recall. The mean DDS $=3.70 s d=1.73$, which was less than the national average of 4 as indicated by Labadarios et al. (2011). About $45 \%$ of adults had a DDS of 3 or less. The results showed that households with 2 persons or less had significantly lower DDS at coefficient 6.71 and $P$-value $=0.035$ and households with 4 persons and above were found to have low DDS, but not significant. There was a significant difference in the DDS for Khayelitsha and Mitchells Plain Pearson $x^{2}=102.9647$ P-value $=0.000$. This difference is because Mitchells Plain consumed more food groups with women in Mitchells Plain having a higher average of DDS compared to women in Khayelitsha. However, the study did not find significant differences in DDS by gender. Other studies have majority of South Africans eat food low in DDS (Labadarios et al., 2011), and this research corroborate such findings.

\section{Identifying Food Components Derivatives}

This section identifies food patterns that were critical in assessing the relationship between food choices and BMI. We used Principal Component Analysis of 12 food groups derived from 36 food types. Using the 12 food groups namely Cereals, White roots, Pulses, Vegetables, Fruits, Meat, Fish, Milk/chees, Sugar, Fat/Oil, Sausages and Beverages, we extracted seven components with the minimum Eigen value (1). These seven components explain $80 \%$ of the variation in the model. The correlation matrix from the sample indicates that there was sufficient correlation between the variables with correlation coefficient $r>4$. The higher the absolute value of the component scores the greater the probability of the food contributing in the overall score of the components (Amugsi et al., 2016; Smith et al., 2013; and McCann et al., 2001). Cereals, Pulses and Milk were loaded on Component 1, Fat and Sausages on component 2, Fish and Sugar on Component 3, vegetable and beverages on Component 4, Meat and meat products loaded on Component 5, White Roots loaded on Component 6 and Fruits loaded highly on Component 7. Given this result, 
we found that there were no clear dietary patterns looking at the components loading. This seem to suggest that despite the reduction of the 36 food types from the dietary recall, the extraction of seven components does not seem to provide a clarity as to people's dietary patterns. However, the first component is evident of high consumption of cereals and milk food types.

Table 5: Association of food patterns to BMI by gender

\begin{tabular}{|c|c|c|c|c|c|c|c|c|c|}
\hline Association & of Food 1 & atterns to & BMI by & ender for $\mathrm{H}$ & hayelits & ta and Mitc & nells Plai & & \\
\hline Khayelitsha & & & & & Miche & s Plain & & & \\
\hline & Men & & Wome & & Men & & Wome & & Pooled \\
\hline $\begin{array}{l}\text { Food } \\
\text { groups }\end{array}$ & Coeff. & p-value & Coeff. & p-value & Coeff. & p >value & Coeff. & p>value & P-value \\
\hline $\begin{array}{l}\text { Cereals, } \\
\text { Pulses } \\
\text { Milk }\end{array}$ & -0.706 & 0.027 & 0.165 & 0.685 & -0.785 & 0.010 & -0.717 & 0.057 & $<0.001$ \\
\hline $\begin{array}{l}\text { Fat and } \\
\text { Sausage }\end{array}$ & -0.495 & 0.204 & -0.696 & 0.135 & -0.141 & 0.690 & -1.11 & 0.004 & $<0.001$ \\
\hline Fish, Sugar & 0.819 & 0.108 & -0.892 & 0.092 & -0.289 & 0.492 & -0.493 & 0.321 & 0.147 \\
\hline $\begin{array}{l}\text { Vegetables } \\
\text { Beverages }\end{array}$ & -0.293 & 0.491 & 0.009 & 0.985 & 0.914 & 0.043 & 0.943 & 0.052 & 0.132 \\
\hline Meat & 0.466 & 0.381 & -0.943 & 0.148 & -0.053 & 0.926 & 0.648 & 0.318 & 0.964 \\
\hline $\begin{array}{l}\text { White } \\
\text { Roots }\end{array}$ & 1.325 & 0.082 & -0.340 & 0.642 & 0.066 & 0.905 & -8.115 & 0.853 & 0.486 \\
\hline Fruits & -0.902 & 0.135 & -0.152 & 0.827 & -0.241 & 0.624 & -8.185 & 0.760 & 0.027 \\
\hline
\end{tabular}

Source: Authors Analysis from empirical data

We assess the association of these components by gender to estimate any difference in terms of components weightings. Using OLS regression analysis presented in Table 5, we found that Component 1=Cereals, Pulses and Milk, for men in Khayelitsha and Michells Plain was significantly associated to BMI compared to women at $\mathrm{p}$-value<0.05 significance level. Women in Khayelitsha showed no significant association with BMI resulting from the consumption of foods within the food patterns. Whereas, there was significant association that a drop in fat and sausages will lead to a drop in BMI for the women in Mitchells Plain, generally, however, three of components/ food pattern showed significant association to BMI. These were Component $1=$ Cereals, Pulses and Milk; Component $2=$ Fat and Sausages and Component 4= Fruits. From these results it can be deduced that urban townships in Cape Town could be experiencing a distorted food lifestyle pattern that is contributing to their high weight gain. 


\section{CONCLUSION}

The focus of this research was to identify the association between Body Mass Index (BMI) in relation to people's food choices and socio-demographic characteristics of people living in Khayelitsha and Mitchells Plain in Cape Town. It is evident that more than $60 \%$ of the population sampled was overweight and obese. The results portray a strong indication of the risk of an increase in overweight and obesity in the study areas. Women continue to show higher prevalence incidences compared to men thus indicating the need for a possible intervention mechanism that aims at reducing weight gain for women in particular.

The food type consumed was predominantly carbohydrate. There is evidence of low consumption of vegetables and fruits which are rich in micro nutrients. The root cause of the increase prevalence of overweight and obesity amongst adults is multidimensional and needs continues multidimensional approaches to underpin the key factors driving weight gain in South Africa, especially in urban peripheral townships. Despite evidence of food choices in this study contributing to weight gain, the results are insufficient and inconclusive. This study found evidence of poor dietary diversity and eating lifestyle to be contributing to weight gain. Majority of households are not only financially poor, but exhibit dietary poverty. Dietary patterns were found to be inconsistent and somewhat distorted and making it difficult to identify a clear dietary patterns. This evidence suggests that the urban peripheral dwellers in Cape Town, majority of which depend on social grants, cannot afford food pattern that is evidence of balanced diet.

Price is often reported as a barrier to the purchase and consumption of healthy foods. Hence, it is recommended that strategies that increase incentives for purchasing healthier food options be pursued. Consumer awareness and programmes that focus on reducing the risk of obesity needs to be put in place in poor communities to address the problem of obesity. In addition, as discussed in this study, to prevent obesity, the multi-sectoral population-based action is required, targeting the most vulnerable group of people. 


\section{REFERENCES}

Adeboye, B., Bermano, G., Rolland, C. (2012). Obesity and its health impact in Africa: a systematic review : review article. Cardiovascular Journal of Africa. 23(9), pp. 512-521.

Amugsi D.A. Dimbuene Z.T. Bakibinga P. Kimani-Murage E.W. Haregu T.N. and Mberu B. (2016). Dietary diversity, socioeconomic status and maternal body mass index (BMI): Quantile regression analysis of nationally representative data from Ghana, Namibia and Sao Tome and Principe. BMJ Open 6, pp. 1 - 12.

Armstrong, M.E., Lambert, M.I., and Lambert, E.V. (2011). Secular trends in the prevalence of stunting, overweight and obesity among South African children (1994-2004). European journal of clinical nutrition, 65(7), pp. 835 - 840.

Ardington, C. and Gasealahwe, B. (2012). Health: Analysis of the NIDS wave 1 and 2 datasets.

Asfaw, A. (2006). The effects of obesity on doctor-diagnosed chronic diseases in Africa: Empirical results from Senegal and South Africa. Journal of Public Health Policy 27(3): 250-264.

City of Cape Town, (2016). Socio-economic Profile: City of Cape Town. Western Cape Government.

Crankshaw, O. Welch, M. and Butcher, S. (2001). GIS technology and survey sampling methods: The Khayelitsha/Mitchell's plain 2000 survey. Social Dynamics (27), pp. 156-174.

de Onis, M. Blössner, M. and Borghi, E. (2010). Global prevalence and trends of overweight and obesity among preschool children. American Journal of Clinical Nutrition (92), pp. $1257-1264$.

Department of Health - DoH, (2006). Annual report - National department of health. Pretoria. DOH, 2006

Department of Health-DoH, (2015). Department of health annualreport South Africa. Retrieved 21 August 2018 (https://www.gov.za/documents/departmenthealth-annual-report-20142015-12-oct-2015-000o)

Devanathan, R., Esterhuizen, T.M. and Govender, R.D., (2013). Overweight and obesity amongst Black women in Durban, KwaZulu-Natal: A 'disease' of perception in an area of high HIV prevalence. African journal of primary health care \& family medicine, 5(1) pp. $1-7$.

Dinbabo, M.F., Karriem, A., Penderis, S. May, J. Fulcher, C., Belebema, M., Mogatosi, T., Zinja P., Gangen, N., Adams, R., and Ngcwayi, N. (2017). Food choices and 
Body Mass Index (BMI) in adults and children: Evidence from the National Income Dynamics Study (NIDS) and empirical research from Khayelitsha and Mitchells Plain in South Africa. Institute for Social Development, University of the Western Cape, Cape Town, South Africa

Du Plooy, Z. Schönfeldt, H. and Hall N. (2018). The role of traditional foods in foodbased dietary guidelines-A South African case study on maas (cultured milk). Food chemistry, (238), pp. 22-28.

Goedecke, J.H. Clark, V.R. Noakes, T.D. and Lambert, E.V. (2005). The effects of medium-chain triacylglycerol and carbohydrate ingestion on ultra-endurance exercise performance. Int J Sport Nutr Exerc Metab. 15(1), pp. 15-27.

Gulliford MC, Mahabir D, Rocke B: (2003). Food insecurity, food choices, and body mass index in adults: nutrition transition in Trinidad and Tobago. International journal of epidemiology, 32(4), pp. 508-516.

Hoffmann, W.A. (2013). A situational analysis of obesity conducted in one South African Community. African Journal of Nursing and Widwifery, 15(2), pp. 115-130.

Human Sciences Research Council (HSRC) and Medical Research Council (MRC). 2013. The South African National Health and Nutrition Examination SurveySANHANES - 1, Pretoria: Human Sciences Research Council.

Jones-Smith, JC.Gordon-Larsen, P. Siddiqi, A. Popkin,BM. (2012). Is the burden of Overweight Shifting to the Poor Across the Globe? Time Trends Among Women in 39 Low-and Middle-income Countries (1991-2008). International journal of Obesity 36(8), pp. 1114-1120.

Kanter R. and Caballero, B. (2012). Global gender disparities in obesity: a review. Adv Nutr. 3(4), pp. 491-8.

Kengne A, Echouffo-Tcheugui J, Sobngwi E, Mbanya J. (2013). New insights on diabetes mellitus and obesity in Africa - Part 1: Prevalence, pathogenesis and comorbidities. Heart, 99(14), pp. 979-983.

Kreuter, F. and Valliant, R. (2007). A Survey on survey statistics: What is done and can be done in Stata." Stata Journal 7, 1.

Kruger, J. Ham, SA. Prohaska, TR. (2009). Behavioral risk factors associated with overweight and obesity among older adults: the 2005 National health interview survey. Prev Chronic Dis, 4(1). pp.1-17.

Kruger,R. Kruger, HS. Macintyre, UE. (2006). The Determinants of overweight and obesity among 10-to 15-year-old schoolchildren in the North West Province, South Africa-the THUSA BANA (Transition and health during urbanisation of South Africans; BANA, children) study. Public health nutrition, 9(3), pp.351-358. 
Labadarios, D. Steyn, NP. Nel, J. (2011). How diverse is the diet of adult South Africans? Nutrition journal, 10(33), pp.1-11.

Loring, B. and Robertson, A. (2014). Obesity and inequities. guidance for addressing inequities in overweight and obesity. Copenhagen: World Health Organization Regional Office for Europe.

Macintyre, S. Ellaway, A. and Cummins, S. (2002). Place effects on health: How can we conceptualise, operationalise and measure them? Social Science \& Medicine, 55, pp.125-139.

Mapumulo, Z. (2015). R23bn in Nine years: Will Obesity Sink SA's Healthcare System? City Press. Retrieved March 6, 2016. (http://city-press.news24.com/News/ R23bn-over-nine-years-and-its-only-getting-worse-20150606)

Maziya, M. Mudhara, M. and Chitja, J. (2017). What factors determine household food security among smallholder farmers? Insights from Msinga, KwaZulu-Natal, South Africa. Agrekon, 56, pp. 40-52.

McCann, S.E., Marshall, J.R., Brasure, J.R., Graham, S., and Freudenheim, J.L. (2001). Analysis of patterns of food intake in nutritional epidemiology: food classification in principal components analysis and the subsequent impact on estimates for endometrial cancer. Public health nutrition, 4(5), pp. 989-997.

Micklesfield, L.K. Lambert, E.V. Hume, D.J. Chantler, S. Pienaar, P.R. Dickie, K. Goedecke, J.H. Puoane, T. Goedecke, J.H. (2013). Socio-cultural, environmental and behavioural determinants of obesity in black South African women : Review articles. Cardiovascular Journal of Africa, 24, pp. 369-375.

Mullie P. Clarys P. Hulens M. Vansant. G. (2011). Socioeconomic, health, and dietary determinants of multivitamin supplements use in Belgium. International journal of public health, 56(3), pp.289-294.

National Institutes of Health Consensus Development Panel (2001). National institutes of health consensus development conference statement: Adjuvant therapy for breast cancer, November 1-3, 2000. JNCI Monographs, 2001(30), pp. 5-15.

NCD Risk Factor Collaboration (2016). Trends in adult body-mass index in 200 countries from 1975 to 2014: A pooled analysis of 1698 population-based measurement studies with 19• 2 million participants. The Lancet, 387(10026), pp. 1377-1396.

Ng, M., Fleming, T., Robinson, M., Thomson, B., Graetz, N., Margono, C., Mullany, E.C., Biryukov, S., Abbafati, C., Abera, S.F., Abraham, J.P., Abu-Rmeileh, N.M.E., Achoki, T., Alemu, Z.A., Alfonso, R., Ali, M.K., Ali, R., Guzman, N.A., Ammar, W., Anwari, P., Banerjee, A., Barquera, S., Basu, S., Bennett, D.A., Bhutta, Z., 
Blore, J., Cabral, N., Nonato, I.C., Chang, J.-C., Chowdhury, R., Courville, K.J., Criqui, M.H., Cundiff, D.K., Dabhadkar, K.C., Dandona, L., Davis, A., Dayama, A., Dharmaratne, S.D., Ding, E.L., Durrani, A.M., Esteghamati, A., Farzadfar, F., Fay, D.F.J., Feigin, V.L., Flaxman, A., Forouzanfar, M.H., Goto, A., Green, M.A., Gupta, R., Hafezi-Nejad, N., Hankey, G.J., Harewood, H.C., Havmoeller, R., Hay, S., Hernandez, L., Husseini, A., Idrisov, B.T., Ikeda, N., Islami, F., Jahangir, E., Jassal, S.K., Jee, S.H., Jeffreys, M., Jonas, J.B., Kabagambe, E.K., Khalifa, S.E.A.H., Kengne, A.P., Khader, Y.S., Khang, Y.-H., Kim, D., Kimokoti, R.W., Kinge, J.M., Kokubo, Y., Kosen, S., Kwan, G., Lai, T., Leinsalu, M., Li, Y., Liang, X., Liu, S., Logroscino, G., Lotufo, P.A., Lu, Y., Ma, J., Mainoo, N.K., Mensah, G.A., Merriman, T.R., Mokdad, A.H., Moschandreas, J., Naghavi, M., Naheed, A., Nand, D., Narayan, K.M.V., Nelson, E.L., Neuhouser, M.L., Nisar, M.I., Ohkubo, T., Oti, S.O.,Pedroza, A., Prabhakaran, D., Roy, N., Sampson, U., Seo, H., Sepanlou, S.G., Shibuya, K., Shiri, R., Shiue, I., Singh, G.M., Singh, J.A., Skirbekk, V., Stapelberg, N.J.C., Sturua, L., Sykes, B.L., Tobias, M., Tran, B.X., Trasande, L., Toyoshima, H., van de Vijver, S., Vasankari, T.J., Veerman, J.L., Velasquez-Melendez, G., Vlassov, V.V., Vollset, S.E., Vos, T.,Wang, C., Wang, X.R., Weiderpass, E., Werdecker, A., Wright, J.L., Yang, Y.C., Yatsuya, H., Yoon, J., Yoon, S.-J., Zhao, Y., Zhou, M., Zhu, S., Lopez, A.D., Murray, C.J.L., Gakidou, E. (2014). Global, regional, and national prevalence of overweight and obesity in children and adults during 1980-2013: a systematic analysis for the Global Burden of Disease Study 2013. The Lancet. (384), pp. 766-781

Perissinotto, E., Pisent, C., Sergi, G., Grigoletto, F., Enzi, G., \& ILSA Working Group. (2002). Anthropometric measurements in the elderly: age and gender differences. British Journal of nutrition, 87(2), 177-186.

Prentice, A.M., 2005. The emerging epidemic of obesity in developing countries. International journal of epidemiology, 35(1), pp.93-99.

Puoane, T. Steyn, K. Bradshaw, D. Laubscher, R. Fourie, J. Lambert, V. and Mbananga, N. (2002). Obesity in South Africa: the South African demographic and health survey. Obesity Research, 10(10), pp. 1038-1048.

Sedibe, H. Kahn, K. Edin, K. Gitau, T. Ivarsson, A. and Norris, SA. (2014). Qualitative study exploring healthy eating practices and physical activity among adolescent girls in rural South Africa. BMC Paediatrics. 14(1), p.211.

Shisana, O., Labadarios, D., Rehle, T., Simbayi, L., Zuma, K., others, (2013). South African national health and nutrition examination survey (SANHANES-1). Cape Town HSRC Press: 135-144.

Skaal, L. and Pengpid, S. (2011). Obesity and Health Problems Among South African Healthcare Workers: Do Healthcare Workers Take Care of Themselves? South African Family Practice 53(6). pp. 563-567. 
Smith, A. D., Emmett, P. M., Newby, P. K., and Northstone, K. (2013). Dietary patterns obtained through principal components analysis: the effect of input variable quantification. British Journal of Nutrition, 109(10), 1881-1891.

Statistics South Africa, (2013). "Annual Report 2013/14 Book 1." Retrieved 21 August 2018 http://www.statssa.gov.za/wp-content/uploads/2014/10/Annual_ Report_2014_Book_1.pdf

Tanumihardjo, S.A., Anderson, C. Kaufer-Horwitz, M. Bode, L. Emenaker, N.J. Haqq, A.M. Satia, J.A Silver H.J., and Stadler. D.D. (2007). Poverty, obesity, and malnutrition: An international perspective recognizing the paradox. Journal of the American Dietetic Association, 107(11). pp. 1966-1972.

Wang, Y. and Beydoun, M. A. (2007). The obesity epidemic in the United Statesgender, age, socioeconomic, racial/ethnic, and geographic characteristics: a systematic review and meta-regression analysis. Epidemiologic reviews, 29(1), 6-28.

World Health Organization, WHO. (2014). "Obesity and Inequities: Guidance for Addressing Inequities in Overweight and Obesity. Regional Office for Europe." World Health Organization. 978(92): 890.

World Health Organization, WHO. (2016). "Obesity and overweight: Fact sheet" Retrieved November 20, 2018 (http://www.who.int/mediacentre/factsheets/ fs311/en/)

Ziraba, A.K. FotsoChristophe, J. and Ochako, R. (2009). Overweight and obesity in urban Africa: A problem of the rich or the poor? BMC Public Health, 9(4659), pp. $1-9$.

\section{Acknowledgement}

This research project was funded by the Programme to Support Pro-Poor Policy Development (PSPPD). It is a European Union-funded research and capacity-building programme located within the South African Department of Planning, Monitoring and Evaluation (DPME) and the Department of Science and Technology/National Research Foundation Centre of Excellence in Food Security. 